\title{
Association of polymorphism of HLA II genes with chronic adrenal insufficiency in APS 2,3,4 types - protective and predisposing genes
}

\begin{abstract}
Introduction: The aim of the study was to determine the association of chronic adrenal insufficiency with polymorphism of HLA II genes among patients with APS 2,3,4 types. The focus of the study was on the revealing of protective genes for Addison's disease in APS 3 type patients.
\end{abstract}

Materials and methods: The case-control study involved 78 patients with APS 2, 3, 4 types and 109 healthy subjects. Alleles of the HLA II class genes, CTLA4 and PTPN22 were identified by the multiprimer allele-specific PCR method. The statistical analysis was carried out using the exact two-sided Fisher test. The association of the chronic adrenal insufficiency in patients with APS was determined by the value of the odds ratio (OR - odd's ratio), the value of $95 \%$ confidence interval $(95 \% \mathrm{CI})$

Results: Haplotypes DR3-DQ2 (OR = 4.06), DR4-DQ8 (OR = 5.78), genotype DR3/ DR4 $(\mathrm{OR}=19.7)$, DQA $1 * 0301$ allele $(\mathrm{OR}=4.27)$, as well as genotype DQA1*0301/ DQA $1 * 0501(\mathrm{OR}=13.89)$ predispose to the development of APS type 2, 3 and 4 in adults compared to the control group. APS patients were divided into two groups according to the presence of Addison's disease (APS 2 and 4 types - and type 3 APS). Haplotype DR3-DQ2 (DRB1*17-DQA1*0501-DQB1*0201) $(\mathrm{OR}=2.6)$, as well as the genotype DR3/DR4 $(\mathrm{OR}=4.28)$ found the strongest association with the development of adrenal insufficiency in patients with APS.

Haplotypes DRB1*01-DQA1*0101-DQB1*0501 (OR =0.07), as well as DRB1*01 $(\mathrm{OR}=0.08)$ have been determined as protective for the development of Addison's disease.

Conclusion: Examination of APS type 3 patients without Addison's disease for the presence of protective genes for the development of adrenal insufficiency will allow better predicting the risks of developing of the disease within the syndrome.

Keywords: autoimmune polyglandular syndrome 2, 3, 4 types, chronic adrenal insufficiency, genes $D R B 1, D Q A 1, D Q B 1 H L A$ class $I$, protective haplotypes
Volume 6 Issue $6-2018$

\section{Troshina Ekaterina Anatolyevna,' Larina Anna Aleksandrovna ${ }^{2}$ \\ 'Russian Academy of Sciences, Deputy Director of Institute of Clinical Endocrinology, Head of Therapeutic Endocrinological Department, Endocrinology Research Centre, Russia ${ }^{2}$ Ph.D. Candidate of Therapeutic Endocrinology, Endocrinology Research Centre, Russia}

\section{Correspondence: Troshina Ekaterina Anatolyevna, Associate Fellow of Russian Academy of Sciences, Professor, Deputy Director of Institute of Clinical Endocrinology, Head of Therapeutic Endocrinological Department, Endocrinology Research Centre. Russia, Tel +7(499) I 2435 02, +7903616 86 47,Email troshena@inbox.ru}

Received: October 29, 2018 | Published: November 27, 2018

\section{Introduction}

Autoimmune polyglandular syndromes (APS) are the combinations of a variety of autoimmune endocrine and non-endocrine diseases represented by the two main types-APS type 1 and APS type 2 . Another two types - APS type 3 and APS type 4 are relating to APS of adults according to classification of clinical character. ${ }^{1,2}$

Nowadays in Russian practice there is no enough focus on diagnostic risks of development the new components of syndrome in APS type 3 patients. Such patients have a combination of autoimmune thyroid disorders with endocrine and non-endocrine autoimmune diseases-Type 1 Diabetes or LADA, vitiligo, alopecia, coeliacia, autoimmune atrophic gastritis, systemic lupus erythematosus, etc. excluding Addison's disease.

The regular examination for the autoimmune markers of the new components of APS, and also revealing of predisposal and protective genes for Addison's disease (HLA DR3, DR4) allow to predict the risk of sudden onset of complications within the syndrome (adrenal crisis and heavy forms of hypoglycemia at the onset of chronic adrenal insufficiency). ${ }^{3}$

\section{Aim}

The Aim of the study was to determine the association of chronic adrenal insufficiency with polymorphism of HLA II genes among patients with APS 2,3,4 types. The focus of the study was on the revealing of protective genes for Addison's disease in APS 3 type patients.

\section{Materials and methods}

Sera of 78 patients with APS type 2, 3, 4 and 109 healthy subjects were screened for HLA II genes' polymorphism. APS patients were at the age of $18-78$ years, women- $74,4 \%$, men- $25,6 \%$. The control healthy group was at the age of $18-58$, among them women- $64,2 \%$, men-35,8 \%/ The difference between two groups was not statistically significant on gender $(\mathrm{p}=0,154)$.

Molecular-genetic examination of HLA II genes was conducted for all patients. DNA from the whole blood of the person was carried out by set of QIAamp DNA Blood Mini Kit (QIAGEN). The method of multyprimer allele-specified polymerase chain reaction was used.

Statistical analysis was carried out by STATISTICA 10, SPSS Statistics with the use of precise two-sided Fisher's test. The differences 
were considered significant with $\mathrm{p}<0,05$. Association with the disease was determinated by OR-odd's ratio and $95 \%$ of confidence interval ( $95 \% \mathrm{CI}$ ). The strong association with the development of the disease was set up with the meaning OR and $95 \% \mathrm{CI}>1$, inverse association with the disease - with OR and $95 \% \mathrm{CI}<1$.

\section{Results}

Addison's disease occurred in $46,2 \%$ cases of APS patients, autoimmune thyroid disorders-in 89,7 \%, chronic autoimmune thyroiditis was represented at $84,3 \%$, Graves' disease had $15,7 \%$ of patients. Autoantibodies to the thyroid tissue (anti-TPO and anti-TG) without thyroid dysfunction were elicited in $5,1 \%$ cases of patients.

Type 1 Diabetes was determined in 56,4 \% cases, among them LADA-in 15,9 \%. The positive level of diabetes-associated autoantibodies (ICA, IA 2, GAD) without increase of glucose level was determined in $7,7 \%$ among all the APS patients.
The prevalence of vitiligo in adult APS patients was $11,5 \%$, alopecia $-5,1 \%$, celiac disease $-2,56 \%$.

APS patients were separated into 2 groups- APS type 2 and 4 with chronic adrenal insufficiency $(\mathrm{N}=36)$ and APS type 3 without chronic adrenal insufficiency $(\mathrm{N}=42)$. The two groups had significantly differences in the presence of type 1 Diabetes (33\% patients had type 1 diabetes in the group of APS type 2,4 against $90 \%$ of APS type 3 ( $p<$ 0,01 ). Thyroid autoimmune diseases (AITD/Grave's disease) existed in $89 \%$ of cases in the group of APS types 2,4 and in $100 \%$ - in the group of APS type 3 (according the classification of APS) $(p<0,05)$. The groups of patients with APS type 2,4 and APS type 3 did not differ strongly according the frequency of occurrence of vitiligo $-6 \%$ against $17 \%$ in accordance $(\mathrm{p}=0,17)$ and alopecia $6 \%$ against $5 \%$ in accordance $(\mathrm{p}=1,0)$.

The frequencies of predisposing and protective $H L A$ II alleles in the group of APS of adults and control group are represented in the Table 1.

\begin{tabular}{|c|c|c|c|c|c|}
\hline \multirow[t]{2}{*}{ HLA II (allele/haplotype/genotype) } & \multicolumn{2}{|c|}{ APS $\mathbf{N = 7 8}$} & \multicolumn{2}{|c|}{$\begin{array}{l}\text { Control group } \\
N=109\end{array}$} & \multirow{2}{*}{$\begin{array}{l}\text { APS vs. control group } \\
\text { P } \\
\text { OR; } 95 \% \mathrm{Cl}\end{array}$} \\
\hline & $\mathrm{N}$ & $\%$ & $\mathrm{n}$ & $\%$ & \\
\hline$D R 3-D Q 2$ & 34 & 21,8 & 14 & 6,4 & $\begin{array}{l}\mathrm{P}<0,000 \mathrm{I} \\
\text { OR } 4.0609 \\
95 \% \mathrm{Cl} 2.0955-7.8695\end{array}$ \\
\hline DR4-DQ8 & 49 & 31,4 & 16 & 7,3 & $\begin{array}{l}\mathrm{P}<0,000 \mathrm{I} \\
\text { OR } 5.78 \mathrm{I} 5 \\
95 \% \mathrm{Cl} 3.1380-10.6520\end{array}$ \\
\hline $\begin{array}{l}D R 3-D Q 21 \\
D R 4-D Q 8\end{array}$ & 21 & 26,9 & 2 & $\mathrm{I}, 8$ & $\begin{array}{l}\mathrm{P}<0,000 \mid \\
\text { OR I9.7I05 } \\
95 \% \mathrm{Cl} 4.46 \mid 8-87.0743\end{array}$ \\
\hline$D R B I * 0 I$ & 14 & 8,9 & 27 & 12,4 & $\mathrm{p}=0,32$ \\
\hline$D R B I * 07$ & 10 & 6,4 & 31 & 14,2 & $\begin{array}{l}\mathrm{p}<0,02 \\
\text { OR } 0.4132 \\
95 \% \mathrm{Cl} 0.1962-0.8703\end{array}$ \\
\hline$D R B / * 13$ & 7 & 4,5 & 29 & 13,3 & $\begin{array}{l}\mathrm{p}<0,01 \\
\text { OR } 0.3062 \\
95 \% \mathrm{Cl} 0.1305-0.7184\end{array}$ \\
\hline$D R B I * 0 I-D Q A I * 010 I-D Q B I * 050 I$ & 14 & 8,9 & 24 & 11 & $\mathrm{P}=0,60$ \\
\hline$D R B|* 07-D Q B| * 0201$ & 8 & 5,1 & 25 & 11,5 & $\begin{array}{l}\mathrm{P}<0,05 \\
\text { OR } 0.4173 \\
95 \% \mathrm{Cl} 0.1830-0.9517\end{array}$ \\
\hline$D R B|*| I-D Q A|* 050 I-D Q B| * 030 I$ & 11 & 7,1 & 34 & 15,6 & $\begin{array}{l}\mathrm{P}<0,02 \\
\text { OR } 0.4105 \\
95 \% \mathrm{Cl} 0.201 \mathrm{I}-0.8383\end{array}$ \\
\hline$D R B I *|5-D Q A| * 0102-D Q B I * 0602 / 8$ & 7 & 4,5 & 6 & 2,6 & $p=1,0$ \\
\hline$D Q A I * 030 I$ & 54 & 34,6 & 24 & 11 & $\begin{array}{l}\mathrm{p}<0,000 \mathrm{I} \\
\text { OR } 4.2794 \\
95 \% \mathrm{Cl} 2.5006-7.3236\end{array}$ \\
\hline$D Q A I * 0501$ & 52 & 33,3 & 54 & 24,8 & $\mathrm{p}=0,08$ \\
\hline$D Q A I * 0301 / D Q A I * 0501$ & 27 & 34,6 & 4 & 3,7 & $\begin{array}{l}p<0,000 I \\
\text { OR I3.897। } \\
95 \% \mathrm{Cl} 4.6163-41.8363\end{array}$ \\
\hline
\end{tabular}

Comparing the two groups of patients with APS 2,3,4 types and patients from the control group the association of haplotypes $D R 3$ $D Q 2(D R B 1 * 0301-D Q A 1 * 0501-D Q B 1 * 0201), D R 4-D Q 8(D R B 1 * 04$ $D Q A 1 * 0301-D Q B 1 * 0302$ ), and also genotype $D R 3-D Q 2 / D R 4-D Q 8$ was elicited with the development of the syndrome (Fisher exact, two-tailed $-\mathrm{p}<0,0001) ; \mathrm{OR}=4.0609,95 \% \mathrm{CI}[2.0955-7.8695]$ $\mathrm{OR}=5.781595 \%$, СІ [3.1380 - 10.6520] и $\mathrm{OR}=19.7105,95 \%$ CI [4.4618 - 87.0743] in accordance.

In the Table 2 there are frequencies of predisposing and protective haplotypes of HLA II genes for APS type 2, 4 and APS type 3. 


\begin{tabular}{|c|c|c|c|c|c|c|c|c|c|}
\hline \multirow[t]{2}{*}{ HLA II } & \multicolumn{2}{|c|}{$\begin{array}{l}\text { Control group } \\
N=109\end{array}$} & \multicolumn{2}{|c|}{$\begin{array}{l}\text { APS } 2,4 \\
\text { (chronic adrenal } \\
\text { insufficiency }+ \text { ) } \\
\mathrm{N}=36\end{array}$} & \multicolumn{2}{|c|}{$\begin{array}{l}\text { APS } 3 \\
\text { (chronic adrenal } \\
\text { insufficiency -) } \\
\mathrm{N}=42\end{array}$} & \multirow{2}{*}{$\begin{array}{l}\text { APS } 2,4 \text { vs. } \\
\text { APS } 3 \\
\%\end{array}$} & \multirow{2}{*}{$\begin{array}{l}\text { APS } 2,4 \text { vs. } \\
\text { Control group } \\
n\end{array}$} & \multirow{2}{*}{$\begin{array}{l}\text { APS } 3 \text { vs. } \\
\text { Control } \\
\text { group }\end{array}$} \\
\hline & $N$ & & $\%$ & & $N$ & & & & \\
\hline$D R 3-D Q 2$ & 14 & 6,4 & 22 & 30,5 & 12 & 14.2 & $\begin{array}{l}\mathrm{P} \\
\mathrm{OR} ; \mathrm{Cl}\end{array}$ & $\begin{array}{l}\mathrm{P} \\
\mathrm{OR} ; \mathrm{Cl}\end{array}$ & $\begin{array}{l}\mathrm{P} \\
\mathrm{OR} ; \mathrm{Cl}\end{array}$ \\
\hline$D R 4-D Q 8$ & 16 & 7,3 & 21 & 29,2 & 28 & 33,3 & $\begin{array}{l}P<0,02 \\
\text { OR } 2.6400 \\
95 \% \mathrm{Cl} \\
1.1975- \\
5.8201\end{array}$ & $\begin{array}{l}P<0,0 \mid \\
\text { OR } 6.4|| 4 \\
95 \% \mathrm{Cl} \\
3.0650- \\
|3.4| \mid 4\end{array}$ & $\begin{array}{l}\mathrm{P}<0,05 \\
\text { OR } 2.4286 \\
95 \% \mathrm{Cl} \\
1.0733- \\
5.4950\end{array}$ \\
\hline \multirow[t]{3}{*}{$\begin{array}{l}D R 3-D Q 2 / \\
D R 4-D Q 8\end{array}$} & 2 & 1,8 & 15 & 42 & 6 & 14 & $P=0,6 I$ & $\begin{array}{l}P<0,000 \text { I } \\
\text { OR } 5.1985 \\
95 \% \mathrm{Cl} \\
2.5322- \\
10.6724\end{array}$ & $\begin{array}{l}P<0,0001 \\
\text { OR } 6.3125 \\
95 \% \mathrm{Cl} \\
3.1921- \\
12.4832\end{array}$ \\
\hline & & & & & & & $\begin{array}{l}P<0,01 \\
\text { OR } 4.2857\end{array}$ & $\begin{array}{l}P<0,0001 \\
\text { OR 38.2 I } 43\end{array}$ & $\begin{array}{l}P<0,0 \text { I } \\
\text { OR } 8.9167\end{array}$ \\
\hline & 27 & 12,4 & I & $\mathrm{I}, 4$ & 13 & 15,5 & $\begin{array}{l}95 \% \mathrm{Cl} \\
1.4423- \\
12.7347\end{array}$ & $\begin{array}{l}95 \% \mathrm{Cl} \\
8.1286- \\
179.6532\end{array}$ & $\begin{array}{l}95 \% \mathrm{Cl} \\
\mathrm{I} .7223- \\
46.1644\end{array}$ \\
\hline$D R B I * 07$ & 31 & 14,2 & 5 & 6,9 & 5 & 5,9 & $\begin{array}{l}P<0,01 \\
\text { OR } 0.0769 \\
95 \% \mathrm{Cl} \\
0.0098- \\
0.6038\end{array}$ & $\begin{array}{l}P<0,01 \\
\text { OR } 0.0996 \\
95 \% \mathrm{Cl} \\
0.0133- \\
0.7469\end{array}$ & $P=0,46$ \\
\hline$D R B / * / 3$ & 29 & 13,3 & I & $\mathrm{I}, 4$ & 6 & 7,1 & $P=I, 0$ & $P=0,15$ & $\begin{array}{l}\mathrm{P}<0,05 \\
\text { OR } 0.3818 \\
95 \% \mathrm{Cl} \\
0.1432- \\
1.0178\end{array}$ \\
\hline $\begin{array}{l}D R B I * 0 I- \\
D Q A I * 0 I 0 I- \\
D Q B I * 050 I\end{array}$ & 24 & II & I & $\mathrm{I}, 4$ & 13 & 15,5 & $P=0,12$ & $\begin{array}{l}P<0,01 \\
\text { OR } 0.0918 \\
95 \% \mathrm{Cl} \\
0.0123- \\
0.6865\end{array}$ & $P=0,16$ \\
\hline $\begin{array}{l}D R B I * 07- \\
D Q B I * 020 I\end{array}$ & 25 & 11,5 & 3 & 4,1 & 5 & 5,9 & $\begin{array}{l}P<0,01 \\
\text { OR } 0.0769 \\
95 \% \mathrm{Cl} \\
0.0098- \\
0.6038\end{array}$ & $\begin{array}{l}P<0,0 \text { I } \\
\text { OR } 0.1138 \\
95 \% \mathrm{Cl} \\
0.0151- \\
0.8572\end{array}$ & $P=0,33$ \\
\hline $\begin{array}{l}D R B I * I I- \\
D Q A I * 050 I- \\
D Q B I * 030 I\end{array}$ & 34 & 15,6 & 6 & 8,3 & 5 & 5,9 & $P=0,73$ & $P=0, I I$ & $P=0,19$ \\
\hline $\begin{array}{l}D R B I * I 5- \\
D Q A I * 0102- \\
D Q B I * 0602 / 8\end{array}$ & 6 & 2,6 & 5 & 6,9 & 2 & 2,4 & $P=0,76$ & $P=0,17$ & $\begin{array}{l}P<0,05 \\
\text { OR } 0.3425 \\
95 \% \mathrm{Cl} \\
0.1292- \\
0.9082\end{array}$ \\
\hline$D Q A I * 030 I$ & 24 & II & 22 & 30,6 & 32 & 38,1 & $P=0,25$ & $P=0,66$ & $P=I, 0$ \\
\hline$D Q A I * 050 I$ & 54 & 24,8 & 33 & 45,8 & 19 & 22,6 & $P=0,39$ & $\begin{array}{l}\mathrm{P}<0,0 \mathrm{I} \\
\text { OR } 3.5567 \\
95 \% \mathrm{Cl} \\
1.8443- \\
6.8591\end{array}$ & $\begin{array}{l}P<0,0001 \\
\text { OR } 4.9744 \\
95 \% \mathrm{Cl} \\
2.6991- \\
9.1677\end{array}$ \\
\hline $\begin{array}{l}D Q A I * 0301 / \\
D Q A I * 050 I\end{array}$ & 4 & 3,7 & 16 & 44,4 & II & 26,2 & $\begin{array}{l}P<0,01 \\
\text { OR } 2.8947 \\
95 \% \mathrm{Cl} \\
1.4518- \\
5.7717\end{array}$ & $\begin{array}{l}P<0,01 \\
\text { OR } 2.5698 \\
95 \% \mathrm{Cl} \\
1.4733- \\
4.4823\end{array}$ & $P=0,77$ \\
\hline
\end{tabular}


Comparing APS type 2, 4 (with chronic adrenal insufficiency) and APS type 3 (without chronic adrenal insufficiency) and also control group significant increasing of frequency of haplotype $D R 3-D Q 2$ $(D R B 1 * 17-D Q A 1 * 0501-D Q B 1 * 0201)$ was identified in patients from both groups with APS of adults in comparison with the control group. For the APS type 2, 4 against healthy control group- $(\mathrm{p}<0,01)$; $\mathrm{OR}=6.4114,95 \% \mathrm{CI}$ [3.0650 -13.4114$]$; for the group of APS type 3 against healthy control group- $(\mathrm{p}<0,05)$; OR $=2.4286,95 \%$ CI [1.0733-5.4950] in accordance.

Increasing of frequency of haplotype $D R 3-D Q 2$ in patients with APS type 2, 4 in comparison with APS type 3 may indicate the association of this haplotype with the development of chronic adrenal insufficiency, independently from other autoimmune diseases $(\mathrm{p}<$ $0,02) ; \mathrm{OR}=2.6400,95 \% \mathrm{CI}[1.1975-5.8201]$.

Association of haplotype DR4-DQ8 (DRB1*04-DQA1*0301$D Q B 1 * 0302)$ was determinated with the development both APS type 2, $4(\mathrm{p}<0,0001) ; \mathrm{OR}=5.1985,95 \%$ CI [2.5322 -10.6724], and APS type 3 ( $\mathrm{p}<0,0001) ; \mathrm{OR}=6.3125,95 \%$ CI [3.1921-12.4832] separately.

Presence of heterozygote genotype $D R 3-D Q 2 / D R 4-D Q 8$ in patients with APS types 2, 4 considerably increases the risk of development of the disease in comparison with control group $(p<0,0001) ; \quad O R=38.2143,95 \%$ CI [8.1286-179.6532] and with group of patients with APS type $3(\mathrm{p}<0,01) ; \mathrm{OR}=4.2857,95 \% \mathrm{CI}$ [1.4423-12.7347]. It is an independent risk factor of development of APS type 2, 4. Frequency of occurrence of heterozygote genotype $D R 3-D Q 2 / D R 4-D Q 8$ in patients with APS type 3 is also higher in comparison with the control group $(\mathrm{p}<0,01) ; \mathrm{OR}=8.9167,95 \% \mathrm{CI}$ [1.7223-46.1644].

According to the results of this study the incidence of $D Q A 1 * 0301$ allele is significantly higher in patients with APS of adults compared to the control group $(\mathrm{p}<0.0001)$; OR $=4.2794,95 \%$ CI $[2.5006$ 7.3236], and the presence of the genotype $D Q A 1 * 0301 / D Q A 1 * 0501$ also significantly increases the risk APS of adults in comparison with the control group $(\mathrm{p}<0.0001)$; OR $=13.8971,95 \%$ CI $[4.6163$ 41.8363].

Besides predisposing genes to the development of chronic adrenal insufficiency, there are also protective. According to Betterle et al $D R 1, D R 7, D R 13$ and $D R 14$ are such genes for APS 2 type, frequency of which significantly higher in the control group in comparison with patients with APS type $2(\mathrm{p}<0,05){ }^{2}$

Thus, in particular, there is a negative correlation of the development of autoimmune primary adrenal insufficiency with the presence of haplotypes DRB1*0101-DQA1*0101-DQB1*0501 (p $<0.0001)[8,13], D R B 1 * 0701-D Q B 1 * 0202[14]$ and $D R B 1 * 13(\mathrm{p}$ $<0,02) ., 4,6$

In this study, among the protective HLA II alleles (Table 1), there was a significant increase of the frequency of occurrence alleles $D R B 1 * 07(\mathrm{p}<0.02) ; \mathrm{OR}=0.4132,95 \%$ CI [0.1962-0.8703], $D R B 1 * 13(\mathrm{p}<0.01) ; \mathrm{OR}=0.3062,95 \%$ CI [0.1305 - 0.7184], as well as haplotype $D R B 1 * 07-D Q B 1 * 0201(\mathrm{p}<0.05) ; \mathrm{OR}=0.4173,95 \%$ CI $[0.1830-0.9517]$ and $D R B 1 * 11-D Q A 1 * 0501-D Q B 1 * 0301$ (p $<0.02)$; OR $=0.4105,95 \%$ CI $[0.118-0.8383]$ in the control group compared to the group of APS patients.

$D R B 1 * 01$ allele was determined as a protective one to the development of APS type 2 and 4 comparing with the group of APS type 3 and the control group (Table 2).
There was a significant decrease of the frequency of occurrence $D R B 1^{*} 01$ allele in APS type 2 and 4 patients compared to the group of patients with APS type $3(\mathrm{p}<0.01)$; OR $=0.0769,95 \%$ CI $[0.0098$ $0.6038]$ and the control group $(\mathrm{p}<0.01)$; $\mathrm{OR}=0.0996,95 \%$ CI $[0.0133$ 0.7469]. Separately, no association was found for patients with APS type 3 .

There was a decrease in the frequency of occurrence of the $D R B 1 * 13$ allele among patients with APS type 2 and 4 in comparison with the control group $(\mathrm{p}<0.01) ; \mathrm{OR}=0.0918,95 \%$ CI $[0.0123$ $0.6865]$, which may indicate its protective properties with respect to the development of chronic adrenal insufficiency in APS of adults. However, significant statistical differences in the incidence of the $D R B 1 * 13$ allele in the group of APS type 2 and type 4 and the group of APS type 3 were not found.

Haplotype $D R B 1 * 01-D Q A 1 * 0101-D Q B 1 * 0501$ is associated with the absence of chronic adrenal insufficiency in APS. Frequency of this haplotype significantly lower in the group of APS type 2 and 4 in comparison with the group of patients with APS type 3 ( $\mathrm{p}<0,01)$; $\mathrm{OR}=0.0769,95 \% \mathrm{CI}[0.0098-0.6038]$, and also in comparison with the control group $(\mathrm{p}<0,01) ; \mathrm{OR}=0.1138,95 \%$ CI [0.0151 -0.8572]. Differences of frequency of this haplotype in patients with APS type 3 and in the control group are statistically unreliable.

\section{Discussion}

A strong association of haplotypes $D R 3-D Q 2, \quad D R 4-D Q 8$, especially of genotype $D R 3 / D R 4$, allele $D Q A 1 * 0301$, and also of genotype $D Q A 1 * 0301 / D Q A 1 * 0501$, with the development of APS of adults was confirmed.

The results of the research for the frequencies of predisposing haplotypes of HLA II genes DR3-DQ2, DR4-DQ8 and also genotype $D R 3-D Q 2 / D R 4-D Q 8$ are similar to the results of international studies, conducted among different populations. According to Norwegian and Italian research the frequency of chronic adrenal insufficiency in APS type 2 significantly increased with the occurrence of haplotypes $D R 3$ $D Q 2$ and $D R 4-D Q 8.5,6,7$

When the groups were divided into APS with the chronic adrenal insufficiency (APS 2 and 4 types) and APS without it (APS type 3), the strongest influence on the risk of the development of chronic adrenal insufficiency in APS had haplotype DR3-DQ2 (DRB1* $17-D Q A 1 * 0501-D Q B 1 * 0201)$, as well as genotype $D R 3 / D R 4$. This fact can serve as an unfavorable prognostic sign for the development of chronic adrenal insufficiency in APS type 3 and require more thorough regular screening in such patients and their relatives with autoimmune diseases.

There were no statistically significant differences in the prevalence of haplotype DR4-DQ8 in the APS group with chronic adrenal insufficiency or without chronic adrenal insufficiency.

According to the work of Huang and co-authors the association with haplotype $H L A D R 4-D Q B 1 * 0302$ in patients with APS type 2 was traced only with type 1 Diabetes. ${ }^{8}$

The results of Myhre and co-writers data indicated the significant association of development of Addison's disease with the haplotypes $D R B 1 * 0404-D Q A 1 * 0301-D Q B 1 * 0302$, and DRB1*0301$D Q A 1 * 0501-D Q B 1 * 0201$, especially with the heterozygote genotype DR3-DQ2/DR4-DQ8. ${ }^{6}$ 
According to the data received from Albergoni and co-writers in which APS 2 type patients were included $(n=54)$, and also materials by Erichsen and co-writers, in which there were patients with the primary chronic adrenal insufficiency $(\mathrm{n}=425)$, the association of both haplotypes DR3-DQ2 and DR4-DQ8 HLA II class was revealed with the development of primary chronic adrenal insufficiency independently from existence of type 1 Diabetes and autoimmune thyroid disease. ${ }^{3,7}$

Also, in foreign studies the effect of separate alleles on the development of APS was found. An increased occurrence of $D Q A 1 * 0301$ in APS type 2 and 3 was determined in comparison with isolated autoimmune diseases, which is an additional risk factor for the development of APS. ${ }^{9}$

The predisposal haplotypes $D R 3-D Q 2, \quad D R 4-D Q 8$, allele $D Q A 1^{*} 0301$ and especially genotype $D R 3 / D R 4$ play an important role in forecasting the development of the APS type 2.

The presence of the protective alleles $D R B 1 * 07, D R B 1 * 13$, as well as haplotypes $D R B 1 * 07-D Q B 1 * 0201$ and $D R B 1 * 07-D Q B 1 *$ 0201 is inversely related to the probability of onset of APS of adults, which indicates their protective nature with respect to the development of the disease as a whole (APS type 2, 3 and 4).

Herewith the presence of protective haplotype $D R B 1^{*} 01$ $D Q A 1 * 0101-D Q B 1 * 0501$, and also allele $D R B 1 * 01$, and $D R B 1 * 13$, in relation to development of chronic adrenal insufficiency in APS type 3 oppositely allows to predict more favorable course of the syndrome. Screening for the development of chronic adrenal insufficiency in APS type 3 patients with protective haplotypes HLA II is possible in standard terms - 1 time in 5 years.

\section{Information about financing and conflict between interests}

The authors emphasize about absence of express or implied conflicts of interests, connected with conducting of this research and publication of this article.

\section{Author contribution statement}

Troshina E.A. - formulation of the purpose and objectives of the study, development of the research concept, checking the text of the article.

Larina A.A. - patient recruitment, static processing of received data, writing an article.

\section{Acknowledgements}

None.

\section{Conflict of interest}

Authors declare there is no conflict of interest in publishing the article

\section{References}

1. Endokrinologiya: natsional'noe rukovodstvo/pod red. Dedova I.I., Mel'nichenko G.A.- M: GEOTAR-Media, 2016. pp. 1081-1088.

2. Betterle $C$, Zanchetta $R$. Update on autoimmune polyendocrine syndromes (APS). Acta Biomed. 2003;74(1):9-33.

3. Erichsen M, Lovas K, Skinningsrud B, et al. Clinical, Immunological, and Genetic Features of Autoimmune Primary Adrenal Insufficiency: Observations from a Norwegian Registry. $J$ Clin Endocrinol Metab. 2009;94(12):4882-4890.

4. Baker P, Fain P, Kahles H, et al. Genetic determinants of 21-hydroxylase autoantibodies amongst patients of the Type 1 Diabetes Genetics Consortium. J Clin Endocrinol Metab. 2012;97(8):E1573-E1578.

5. Betterle C, Lazzarotto F, Presotto F. Autoimmune polyglandular syndrome Type 2: the tip of an iceberg? Clin Exp Immunol. 2004;137(2):225-233.

6. Myhre AG, Undelien DA, Lovas K, et al. Autoimmune adrenocortical failure in Norway autoantibodies and human leukocyte antigen class II association related to clinical features. J Clin Endocr Metab. 2002;87(2):618-623

7. Albergoni P, Gazzola MV, Slanzi E. $H L A-D R$ and $D Q$ associations with autoimmune Addison's disease in Italian patients Genes. Immunity. 2003;4(1):S35.

8. Huang W, Connor E, Dela Rosa T, et al. Although DR3-DQB1*0201 may be associated with multiple component diseases of the Autoimmune Polyglandular Syndrome, the Human Leukocyte Antigen DR4$D Q B 1 * 0302$ haplotype is implicated only in beta-cells autoimmunity. $J$ Clin Endocrinol Metab. 1996;81(7):2259-2263.

9. Wallaschofski H, Meyer A, Tuschy U, et al. HLA-DQA1*0301-associated susceptibility for autoimmune polyglandular syndrome type II and III. Horm Metab Res. 2003;35(2):120-124. 